\title{
Electrical Activity of the Heart in the Older Adults Suffering from Chronic Kidney Disease: Ethnic and Age Characteristics
}

\author{
Polina I. Kudrina ${ }^{1,3}$, PhD; Svetlana S. Shadrina ${ }^{2}$; Sargylana I. Sofronova ${ }^{3}, \mathrm{PhD}$; \\ Anna N. Bogolepova ${ }^{4}$; Ariadna A. Donskaya ${ }^{2}$; Natalya V. Borisova ${ }^{2}$; \\ Andrey P. Karelin², PhD \\ ${ }^{1}$ Republican Hospital \#2, Yakutsk, Russia \\ ${ }^{2}$ North-Eastern Federal University, Yakutsk, Russia \\ ${ }^{3}$ Yakut Science Center of Complex Medical Problems, Yakutsk, Russia \\ ${ }^{4}$ N. I. Pirogov Russian National Research Medical University, Moscow, Russia
}

\begin{abstract}
The aim of the study was to investigate the ethnic and age-related characteristics of the electrical activity of the heart in older adults with chronic kidney disease (CKD).

Methods and Results: A total of 522 patients aged between 60 and 89 years with different stages of CKD were examined. For a comparative analysis, we formed 3 ethnic groups (Yakuts, Evens, and Russians) and 2 age groups (60-74 years and 75-89 years). All patients underwent ECG. The laboratory analysis included determining the blood creatinine level for further calculation of the GFR using the Cockcroft\&Gault formula, followed by determining the stage of CKD. A decrease in renal function was more typical for people of 75-89 years. The results of the study confirmed the close relationship of CKD in older adults with the pathology of the cardiovascular system. Changes in the electrical activity of the heart predominated in Russians, compared to other ethnic groups, and were less pronounced in the Evens.(International Journal of Biomedicine. 2021;11(3):351-354.)
\end{abstract}

Key Words: ethnicity $\bullet$ older adults $\bullet$ electrical activity of the heart $\bullet$ chronic kidney disease

For citation: Kudrina PI, Shadrina SS, Sofronova SI, Bogolepova AN, Donskaya AA, Borisova NV, Andrey P. Karelin AP. Electrical Activity of the Heart in the Older Adults Suffering from Chronic Kidney Disease: Ethnic and Age Characteristics. International Journal of Biomedicine. 2021;11(3):351-354. doi:10.21103/Article11(3)_OA12

\section{Abbreviations}

CKD, chronic kidney disease; EAH, electrical activity of the heart; ECG, electrocardiography; GFR, glomerular filtration rate; LVH, left ventricular hypertrophy.

\section{Introduction}

The high incidence of cardiovascular diseases in kidney pathology is well known. ${ }^{(1-3)}$ On the one hand, pathology of the cardiovascular system, according to the results of numerous studies, is the main cause of death in patients with chronic kidney disease $(\mathrm{CKD}){ }^{(4-6)}$ At the same time, in the older adults,

*Corresponding author: Sargylana I. Sofronova, PhD. Yakut Science Center of Complex Medical Problems. Yakutsk, the Republic of Sakha (Yakutia),Russia.E-mail: sara2208@mail.ru the presence of a combination of two or more diseases often aggravates cardiovascular pathology. ${ }^{(7-9)}$ Even mild renal dysfunction in patients with early stages of CKD can increase the risk of ischemic heart disease, myocardial infarction and other cardiovascular complications, significantly worsening the quality and prognosis of life in such patients. ${ }^{(10-12)}$ In this regard, it is important to study the electrical activity of the heart and problems related to cardiorenal relationships in older adults suffering from CKD.

The aim of the study was to investigate the ethnic and age-related characteristics of the electrical activity of the heart (EAH) in older adults with CKD. 


\section{Materials and Methods}

A total of 522 patients aged between 60 and 89 years with different stages of CKD were examined. All patients were divided into 3 groups; their nationality was indicated by self-determination. Group 1 consisted of 174 patients - Evens living in the Arctic zone of Yakutia. Group 2 included 177 patients of Yakut nationality living in the Vilyui zone. Group 3 was comprised 171 patients of Russian nationality living in the Central and Vilyui zones of Yakutia.

The age of the examined patients varied from 60 to 89 years; the average age of the surveyed was $72.7 \pm 7.2$ years ( $72.9 \pm 7.2$ for men and $72.6 \pm 7.2$ for women). The division by age groups was carried out on the basis of the WHO classification: the age group of 60-74 years, the age group of 75-89 years.

The research program included the following sections: informed consent of the respondent to conduct research and donate blood; a thorough and in-depth collection of medical history, review of outpatient medical records from clinics at the place of residence, clinical examination by an internist and nephrologist. All patients underwent ECG. The laboratory analysis included determining the blood creatinine level for further calculation of the GFR using the Cockcroft\&Gault formula, followed by determining the stage of CKD. According to the classification of the KDIGO committee, ${ }^{(13)}$ the stages of CKD, depending on the GFR, were distributed as follows: Stage $1\left(\geq 90 \mathrm{ml} / \mathrm{min} / 1.73 \mathrm{~m}^{2}\right)$, Stage $2(60-89 \mathrm{ml} /$ $\left.\mathrm{min} / 1.73 \mathrm{~m}^{2}\right)$, Stage $3 \mathrm{~A}\left(45-59 \mathrm{ml} / \mathrm{min} / 1.73 \mathrm{~m}^{2}\right)$, and Stage 3B $\left(30-44 \mathrm{ml} / \mathrm{min} / 1.73 \mathrm{~m}^{2}\right)$.

A standard 12-lead ECG was recorded at $50 \mathrm{~mm} / \mathrm{s}$ for $10-$ 12 cycles with a Cardiovit AG-I system (Austria). LVH was defined as a Sokolow-Lyon voltage amplitude of (SV1+RV5 or RV6) $\geq 35 \mathrm{mV}$ and a Cornell product of $[(\mathrm{RaVL}+\mathrm{SV} 3) \times \mathrm{QRS}$ duration] $>2440 \mathrm{mV} \cdot \mathrm{ms}$.

Statistical analysis was performed using IBM SPSS Statistics for Windows, Version 19.0 (Armonk, NY: IBM Corp.). For descriptive analysis, results are presented as median (Me), first quartile (25th percentile) and third quartile (75th percentile). A non-parametric Kruskal-Wallis test was used for comparisons of median values among groups. Categorical variables were analyzed using the Chi-square test with the Yates' correction. A value of $P<0.05$ was considered significant.

The study was approved by the Ethics Committee of the Yakut Science Center of Complex Medical Problems.

\section{Results and Discussion}

Assessment of renal function showed that in both age groups, GFR was statistically significantly lower in Russians than in Yakuts and Evens $(P=0.015)$ (Table 1). In the age group of 75-89 years, we found a decrease in renal function in all ethnic groups; statistically significant differences in age-related GFR were obtained in representatives of the Russian and Yakut nationalities $(P<0.001)$. The data obtained is consistent with the studies of many foreign scientists on the effects of aging on kidney function. ${ }^{(14-16)}$ Renal dysfunction is more common in the group of 75-89 years. Adult Russians of both age groups had an unfavorable background for dysfunction.
Table1.

GFR in each ethnic group, depending on the age category $(\mathrm{ml} / \mathrm{min}$ $/ 1.73 m^{2}$ )

\begin{tabular}{|c|c|c|c|c|}
\hline Age, years & Ethnos & $\mathrm{Me}$ & $\mathrm{Q}_{1}$ & $\mathrm{Q}_{3}$ \\
\hline \multirow{3}{*}{$\begin{array}{c}60-74 \\
(\mathrm{n}=265)\end{array}$} & Evens $(\mathrm{n}=88)$ & 78.5 & 61.5 & 91.75 \\
\cline { 2 - 5 } & Yakuts $(\mathrm{n}=95)$ & 82.0 & 68.0 & 90.0 \\
\cline { 2 - 5 } & Russians $(\mathrm{n}=82)$ & 69.0 & 46.5 & 83.75 \\
\hline \multirow{3}{*}{$\begin{array}{c}75-89 \\
(\mathrm{n}=257)\end{array}$} & Evens $(\mathrm{n}=86)$ & 67.0 & 52.0 & 82.0 \\
\cline { 2 - 5 } & Yakuts $(\mathrm{n}=82)$ & 59.0 & 45.0 & 80.5 \\
\cline { 2 - 5 } & Russians $(\mathrm{n}=89)$ & 40.0 & 35.0 & 52.0 \\
\hline
\end{tabular}

Ethnicity-dependent electrocardiographic changes in different age groups are presented in Table 2. In the group of 60-74 years, LVH was significantly more often recorded among the Yakuts than among compared the Russians (39.0\%) and Evens $(27.3 \%)(P=0.006)$. ECG changes, such as atrial enlargement, tachycardia, atrioventricular block, extrasystole, atrial fibrillation and pathologic $\mathrm{Q}$ waves, were observed more often among the Yakuts and Russians than among compared the Evens; however, the differences were statistically insignificant. In the group of 75-89 years, tachycardia was significantly more often detected in Russians $(P=0.002)$; myocardial infarction was significantly less frequently recorded in Evens (12.8\%) versus $29.3 \%$ in Yakuts and 33.7\% in Russians $(P=0.004)$. Other ECG changes did not have statistically significant differences.

A comparative analysis of combined pathology of the kidneys and the heart, depending on ethnicity and age, was carried out. Table 3 presents electrocardiographic changes, depending on the CKD stages for the age category of 60-74 years and each ethnic group. Among Evens of the age group of 60-74 years, ECG changes did not depend on renal function. Among the Yakuts, tachycardia was more often detected at Stage 3A; among Russians, extrasystoles were more often detected in Stage 3B.

Electrocardiographic changes registered in the age group of 75-89 years depending on the CKD stages are presented in Table 4. In Yakuts of the age group of 75-89 years, ECG changes did not depend on the CKD stage. Among Evens and Russians, atrial enlargement was more common in CKD Stage 3A $(P<0.001)$. In Russians of the age group of $60-74$ years with CKD Stage $3 \mathrm{~A}$, bradycardia was also most often registered $(P<0.001)$.

In conclusion, a decrease in renal function is more typical for people of 75-89 years. The most severe kidney damage is experienced by representatives of the Russian nationality in the age group of 75-89 years. An electrocardiographic study of the state of the heart muscle showed that the frequency of the LVH, which is a sign of long-term arterial hypertension, increased as the stage of CKD progressed. The prevalence of tachycardia and extrasystole can be explained by an increase in the activity of the sympathetic nervous system in patients with $\mathrm{CKD}$, especially when combined with chronic heart failure. Changes in the EAH predominate in Russians, compared to other ethnic groups, and are less pronounced in the Evens. The results of the study confirmed the close relationship of CKD in older adults with the pathology of the cardiovascular system. 
Table 2.

Ethnicity-dependent electrocardiographic changes in different age groups

\begin{tabular}{|c|c|c|c|c|c|c|c|c|c|c|c|c|c|c|c|c|c|}
\hline \multirow{2}{*}{ Age group } & \multirow{2}{*}{ Ethnos } & \multicolumn{2}{|c|}{ LVH } & \multicolumn{2}{|c|}{$\mathrm{AE}$} & \multicolumn{2}{|c|}{$\mathrm{B} / \mathrm{c}$} & \multicolumn{2}{|c|}{$\mathrm{T} / \mathrm{c}$} & \multicolumn{2}{|c|}{ AVB } & \multicolumn{2}{|c|}{$\mathrm{E} / \mathrm{s}$} & \multicolumn{2}{|c|}{$\mathrm{AF}$} & \multicolumn{2}{|c|}{ AQW } \\
\hline & & $\mathrm{n}$ & $\%$ & $\mathrm{n}$ & $\%$ & $\mathrm{n}$ & $\%$ & $\mathrm{n}$ & $\%$ & $\mathrm{n}$ & $\%$ & $\mathrm{n}$ & $\%$ & $\mathrm{n}$ & $\%$ & $\mathrm{n}$ & $\%$ \\
\hline \multirow{5}{*}{$\begin{array}{c}60-74 \\
(n=265)\end{array}$} & $\begin{array}{l}\text { Evens } \\
(\mathrm{n}=88)\end{array}$ & 24 & 27.3 & 3 & 3.4 & 7 & 8.0 & 4 & 4.5 & 2 & 2.3 & 5 & 5.7 & 6 & 6.8 & 14 & 15.9 \\
\hline & $\begin{array}{l}\text { Yakuts } \\
(\mathrm{n}=95)\end{array}$ & 48 & 50.5 & 8 & 8.4 & 10 & 10.5 & 6 & 6.3 & 6 & 6.3 & 10 & 10.5 & 8 & 8.4 & 21 & 22.1 \\
\hline & $\begin{array}{c}\text { Russians } \\
(\mathrm{n}=82)\end{array}$ & 32 & 39.0 & 8 & 9.8 & 12 & 14.6 & 6 & 7.3 & 8 & 9.8 & 13 & 15.9 & 13 & 15.9 & 21 & 25.6 \\
\hline & $\chi^{2}$ & \multicolumn{2}{|c|}{10.36} & \multicolumn{2}{|c|}{2.92} & \multicolumn{2}{|c|}{1.97} & \multicolumn{2}{|c|}{0.6} & \multicolumn{2}{|c|}{4.21} & \multicolumn{2}{|c|}{4.65} & \multicolumn{2}{|c|}{4.29} & \multicolumn{2}{|c|}{2.48} \\
\hline & $P$ & \multicolumn{2}{|c|}{0.006} & \multicolumn{2}{|c|}{0.23} & \multicolumn{2}{|c|}{0.37} & \multicolumn{2}{|c|}{0.74} & \multicolumn{2}{|c|}{0.12} & \multicolumn{2}{|c|}{0.1} & \multicolumn{2}{|c|}{0.12} & \multicolumn{2}{|c|}{0.29} \\
\hline \multirow{5}{*}{$\begin{array}{c}75-89 \\
(n=257)\end{array}$} & $\begin{array}{l}\text { Evens } \\
(\mathrm{n}=86)\end{array}$ & 35 & 40.7 & 10 & 11.6 & 8 & 9.3 & 3 & 3.5 & 3 & 3.5 & 4 & 4.7 & 9 & 10.5 & 11 & 12.8 \\
\hline & $\begin{array}{l}\text { Yakuts } \\
(\mathrm{n}=82)\end{array}$ & 36 & 43.9 & 11 & 13.4 & 12 & 14.6 & 8 & 9.8 & 4 & 4.9 & 11 & 13.4 & 11 & 13.4 & 24 & 29.3 \\
\hline & $\begin{array}{c}\text { Russians } \\
(\mathrm{n}=89)\end{array}$ & 42 & 47.2 & 21 & 23.6 & 15 & 16.9 & 18 & 20.2 & 6 & 6.7 & 12 & 13.5 & 8 & 9.0 & 30 & 33.7 \\
\hline & $\chi^{2}$ & \multicolumn{2}{|c|}{0.75} & \multicolumn{2}{|c|}{5.34} & \multicolumn{2}{|c|}{2.23} & \multicolumn{2}{|c|}{12.52} & \multicolumn{2}{|c|}{0.97} & \multicolumn{2}{|c|}{4.71} & & 39 & & .1 \\
\hline & $P$ & & 69 & & 07 & & 33 & & 02 & & 62 & & 1 & & 64 & & 04 \\
\hline
\end{tabular}

LVH - left ventricular hypertrophy, AE - atrial enlargement, Bc-bradycardia, Tc-tachycardia, E/s - extrasystole, AF-atrial fibrillation, $A Q W$ - abnormal $Q$ waves

Table 3.

Electrocardiographic changes, depending on the CKD stages for the age category of 60-74 years and each ethnic group

\begin{tabular}{|c|c|c|c|c|c|c|c|c|c|c|c|c|c|c|c|c|c|}
\hline \multirow{2}{*}{ Ethnos } & \multirow{2}{*}{$\begin{array}{c}\text { Stage of } \\
\text { CKD }\end{array}$} & \multicolumn{2}{|c|}{ LVH } & \multicolumn{2}{|c|}{$\mathrm{AE}$} & \multicolumn{2}{|c|}{$\mathrm{B} / \mathrm{c}$} & \multicolumn{2}{|c|}{$\mathrm{T} / \mathrm{c}$} & \multicolumn{2}{|c|}{ AVB } & \multicolumn{2}{|c|}{$\mathrm{E} / \mathrm{s}$} & \multicolumn{2}{|c|}{$\mathrm{AF}$} & \multicolumn{2}{|c|}{ AQW } \\
\hline & & $\mathrm{n}$ & $\%$ & $\mathrm{n}$ & $\%$ & $\mathrm{n}$ & $\%$ & $\mathrm{n}$ & $\%$ & $\mathrm{n}$ & $\%$ & $\mathrm{n}$ & $\%$ & $\mathrm{n}$ & $\%$ & $\mathrm{n}$ & $\%$ \\
\hline \multirow{6}{*}{$\begin{array}{c}\text { Evens } \\
(\mathrm{n}=88)\end{array}$} & 1 & 7 & 24.1 & 0 & 0 & 1 & 3.4 & 2 & 6.9 & 2 & 6.9 & 3 & 10.3 & 5 & 17.2 & 2 & 6.9 \\
\hline & 2 & 11 & 28.2 & 2 & 5.1 & 6 & 15.4 & 1 & 2.6 & 0 & 0 & 2 & 5.1 & 1 & 2.6 & 6 & 15.4 \\
\hline & $3 \mathrm{~A}$ & 5 & 31.3 & 1 & 6.3 & 0 & 0 & 0 & 0 & 0 & 0 & 0 & 0 & 0 & 0 & 4 & 25.0 \\
\hline & $3 \mathrm{~B}$ & 1 & 25.0 & 0 & 0 & 0 & 0 & 1 & 25 & 0 & 0 & 0 & 0 & 0 & 0 & 2 & 50.0 \\
\hline & $\chi^{2}$ & \multicolumn{2}{|c|}{0.3} & \multicolumn{2}{|c|}{1.9} & \multicolumn{2}{|c|}{5.47} & \multicolumn{2}{|c|}{5.34} & \multicolumn{2}{|c|}{4.16} & \multicolumn{2}{|c|}{2.4} & \multicolumn{2}{|c|}{7.5} & \multicolumn{2}{|c|}{6.23} \\
\hline & $P$ & \multicolumn{2}{|c|}{0.96} & \multicolumn{2}{|c|}{0.59} & \multicolumn{2}{|c|}{0.14} & \multicolumn{2}{|c|}{0.15} & \multicolumn{2}{|c|}{0.24} & \multicolumn{2}{|c|}{0.49} & \multicolumn{2}{|c|}{0.06} & \multicolumn{2}{|c|}{0.1} \\
\hline \multirow{6}{*}{$\begin{array}{l}\text { Yakuts } \\
(\mathrm{n}=95)\end{array}$} & 1 & 19 & 70.4 & 4 & 14.8 & 2 & 7.4 & 1 & 3.7 & 2 & 7.4 & 2 & 7.4 & 1 & 3.7 & 7 & 25.9 \\
\hline & 2 & 21 & 38.9 & 4 & 7.4 & 7 & 13.0 & 2 & 3.7 & 2 & 3.7 & 7 & 13.0 & 5 & 9.3 & 11 & 20.4 \\
\hline & $3 \mathrm{~A}$ & 6 & 60.0 & 0 & 0 & 1 & 10.0 & 3 & 30.0 & 1 & 10.0 & 0 & 0 & 1 & 10.0 & 3 & 30.0 \\
\hline & $3 B$ & 2 & 50.0 & 0 & 0 & 0 & 0 & 0 & 0 & 1 & 25.0 & 1 & 25.0 & 1 & 25.0 & 0 & 0 \\
\hline & $\chi^{2}$ & \multicolumn{2}{|c|}{7.54} & \multicolumn{2}{|c|}{2.79} & & 09 & & .68 & & 27 & & 69 & & 29 & & 82 \\
\hline & $P$ & & 06 & & 43 & & 78 & & 14 & & 35 & & 44 & & 52 & & 61 \\
\hline & 1 & 2 & 13.3 & 1 & 6.7 & 2 & 13.3 & 2 & 13.3 & 1 & 6.7 & 1 & 6.7 & 1 & 6.7 & 4 & 26.7 \\
\hline & 2 & 19 & 50.0 & 3 & 7.9 & 4 & 10.5 & 3 & 7.9 & 3 & 7.9 & 4 & 10.5 & 8 & 21.1 & 10 & 26.3 \\
\hline Russians & $3 \mathrm{~A}$ & 5 & 50.0 & 3 & 30.0 & 1 & 10.0 & 0 & 0 & 2 & 20.0 & 1 & 10.0 & 1 & 10.0 & 4 & 40.0 \\
\hline$(n=82)$ & $3 \mathrm{~B}$ & 6 & 31.6 & 1 & 5.3 & 5 & 26.3 & 1 & 5.3 & 2 & 10.5 & 7 & 36.8 & 3 & 15.8 & 3 & 15.8 \\
\hline & $\chi^{2}$ & & 03 & & 4 & & 78 & & 73 & & 52 & & 29 & & 98 & & 07 \\
\hline & $P$ & & 07 & & 15 & & 43 & & 63 & & 68 & & 04 & & 58 & & 56 \\
\hline
\end{tabular}

LVH - left ventricular hypertrophy, AE - atrial enlargement, Bc-bradycardia, Tc-tachycardia, E/s - extrasystole, AF-atrial fibrillation, $A Q W$ - abnormal $Q$ waves 
Table 4.

Electrocardiographic changes, depending on the CKD stages for the age category of 75-89 years and each ethnic group

\begin{tabular}{|c|c|c|c|c|c|c|c|c|c|c|c|c|c|c|c|c|c|}
\hline \multirow{2}{*}{ Ethnos } & \multirow{2}{*}{$\begin{array}{l}\text { Stage of } \\
\text { CKD }\end{array}$} & \multicolumn{2}{|c|}{ LVH } & \multicolumn{2}{|c|}{$\mathrm{AE}$} & \multicolumn{2}{|c|}{$\mathrm{B} / \mathrm{c}$} & \multicolumn{2}{|c|}{$\mathrm{T} / \mathrm{c}$} & \multicolumn{2}{|c|}{ AVB } & \multicolumn{2}{|c|}{$\mathrm{E} / \mathrm{s}$} & \multicolumn{2}{|c|}{$\mathrm{AF}$} & \multicolumn{2}{|c|}{ AQW } \\
\hline & & $\mathrm{n}$ & $\%$ & $\mathrm{n}$ & $\%$ & $\mathrm{n}$ & $\%$ & $\mathrm{~N}$ & $\%$ & $\mathrm{n}$ & $\%$ & $\mathrm{n}$ & $\%$ & $\mathrm{n}$ & $\%$ & $\mathrm{n}$ & $\%$ \\
\hline \multirow{6}{*}{$\begin{array}{l}\text { Evens } \\
(\mathrm{n}=86)\end{array}$} & 1 & 7 & 77.8 & 0 & 0 & 1 & 11.1 & 1 & 11.1 & 0 & 0 & 1 & 11.1 & 0 & 0 & 2 & 22.2 \\
\hline & 2 & 16 & 38.1 & 3 & 7.1 & 3 & 7.1 & 2 & 4.8 & 2 & 4.8 & 1 & 2.4 & 4 & 9.5 & 5 & 11.9 \\
\hline & $3 \mathrm{~A}$ & 9 & 36.0 & 7 & 28.0 & 2 & 8.0 & 0 & 0 & 0 & 0 & 1 & 4.0 & 1 & 16.0 & 2 & 8.0 \\
\hline & $3 B$ & 3 & 30.0 & 0 & 0 & 2 & 20.0 & 0 & 0 & 1 & 10.0 & 1 & 10.0 & 1 & 10.0 & 2 & 20.0 \\
\hline & $\chi^{2}$ & \multicolumn{2}{|c|}{5.95} & \multicolumn{2}{|c|}{9.84} & \multicolumn{2}{|c|}{1.67} & \multicolumn{2}{|c|}{3.02} & \multicolumn{2}{|c|}{2.69} & \multicolumn{2}{|c|}{2.0} & \multicolumn{2}{|c|}{1.91} & \multicolumn{2}{|c|}{1.73} \\
\hline & $\mathrm{P}$ & \multicolumn{2}{|c|}{0.11} & \multicolumn{2}{|c|}{0.02} & \multicolumn{2}{|c|}{0.64} & \multicolumn{2}{|c|}{0.39} & \multicolumn{2}{|c|}{0.44} & \multicolumn{2}{|c|}{0.57} & \multicolumn{2}{|c|}{0.59} & \multicolumn{2}{|c|}{0.63} \\
\hline \multirow{6}{*}{$\begin{array}{l}\text { Yakuts } \\
(\mathrm{n}=82)\end{array}$} & 1 & 2 & 100 & 0 & 0 & 0 & 0 & 1 & 50.0 & 0 & 0 & 0 & 0 & 0 & 0 & 0 & 0 \\
\hline & 2 & 18 & 47.4 & 2 & 5.3 & 4 & 10.5 & 3 & 7.9 & 1 & 2.6 & 4 & 10.5 & 4 & 10.5 & 12 & 31.6 \\
\hline & $3 \mathrm{~A}$ & 10 & 41.7 & 5 & 20.8 & 5 & 20.8 & 2 & 8.3 & 1 & 4.2 & 5 & 20.8 & 5 & 20.8 & 7 & 29.2 \\
\hline & $3 \mathrm{~B}$ & 6 & 33.3 & 4 & 22.2 & 3 & 16.7 & 2 & 11.1 & 2 & 11.1 & 2 & 11.1 & 2 & 11.1 & 5 & 27.8 \\
\hline & $\chi^{2}$ & \multicolumn{2}{|c|}{3.61} & \multicolumn{2}{|c|}{4.82} & & & & 92 & & .05 & & .8 & & 1.8 & & 95 \\
\hline & $\mathrm{P}$ & & 31 & & 19 & & & & 27 & & .56 & & 61 & & .61 & & 82 \\
\hline & 1 & - & - & - & - & - & - & - & - & - & - & - & - & - & - & - & - \\
\hline & 2 & 5 & 62.5 & 0 & 0 & 0 & 0 & 2 & 25.0 & 1 & 12.5 & 1 & 12.5 & 0 & 0 & 2 & 25.0 \\
\hline Russians & $3 \mathrm{~A}$ & 17 & 56.7 & 15 & 50.0 & 13 & 43.3 & 4 & 13.3 & 2 & 6.7 & 4 & 13.3 & 3 & 10.0 & 15 & 50.0 \\
\hline$(\mathrm{n}=89)$ & $3 \mathrm{~B}$ & 20 & 39.2 & 6 & 11.8 & 2 & 3.9 & 12 & 23.5 & 3 & 5.9 & 7 & 13.7 & 5 & 9.8 & 13 & 25.5 \\
\hline & $\chi^{2}$ & & 14 & & & & & & 34 & & .48 & & .01 & & .87 & & 38 \\
\hline & $\mathrm{P}$ & & 21 & & 001 & & 001 & & 51 & & .79 & & .99 & & .65 & & 97 \\
\hline
\end{tabular}

\section{References}

1. Moiseev VS, Kobalava ZhD. [Cardiorenal syndrome (renal factor and increased risk of cardiovascular disease)]. Clin Pharm Therapy. 2002;11(3):16-18. [Article in Russian]. 2. Smirnov AV, Dobronravov VA, Kayukov IG. [Cardiorenal continuum: pathogenetic foundations of preventive nephrology]. Nephrology (Saint-Petersburg). 2005;9(3):7-15. [Article in Russian].

3. Shutov AM, Serov VA. [Cardiorenal continuum or cardiorenal syndrome]. Clinical Nephrology. 2010;1:44-48. [Article in Russian].

4. McCullough PA, Ahmad A. Cardiorenal syndromes. World J Cardiol. 2011 Jan 26;3(1):1-9. doi: 10.4330/wjc.v3.i1.1.

5. Meisinger C, Döring A, Löwel H; KORA Study Group. Chronic kidney disease and risk of incident myocardial infarction and all-cause and cardiovascular disease mortality in middle-aged men and women from the general population. Eur Heart J. 2006;27(10):1245-50. doi: 10.1093/eurheartj/ehi880.

6. Vanholder R, Massy Z, Argiles A, Spasovski G, Verbeke F, Lameire N; European Uremic Toxin Work Group. Chronic kidney disease as cause of cardiovascular morbidity and mortality. Nephrol Dial Transplant. 2005;20(6):1048-56.

7. Smilde TD, Hillege HL, Navis G, Boomsma F, de Zeeuw $\mathrm{D}$, van Veldhuisen DJ. Impaired renal function in patients with ischemic and nonischemic chronic heart failure: association with neurohormonal activation and survival. Am Heart J. 2004 Jul;148(1):165-72. doi: 10.1016/j.ahj.2004.02.007.

8. van der Velde M, Matsushita K, Coresh J, Astor BC, Woodward M, Levey A, de Jong P, et al. Lower estimated glomerular filtration rate and higher albuminuria are associated with all-cause and cardiovascular mortality. A collaborative meta-analysis of high-risk population cohorts. Kidney Int. 2011 Jun;79(12):1341-52. doi: 10.1038/ki.2010.536.

9. US Renal Data System. USRDS 2003 Annual Data Report: Atlas of End-Stage Renal Disease in the United States. National Institutes of Health; National Institute of Diabetes and Digestive and Kidney Diseases, Bethesda, MD 2003.

10. Mukhin NA. [A decreased glomerular filtration rate as a general population marker of an unfavorable prognosis]. Ter Arkh. 2007;79(6):5-10. [Article in Russian].

11. Schmieder RE, Schrader J, Zidek W, Tebbe U, Paar WD, Bramlage P, Pittrow D, Böhm M. Low-grade albuminuria and cardiovascular risk: what is the evidence? Clin Res Cardiol. 2007 May;96(5):247-57. doi: 10.1007/s00392-007-0510-3.

12. Segura J, Campo C, Ruilope LM. Effect of proteinuria and glomerular filtration rate on cardiovascular risk in essential hypertension. Kidney Int Supp.1 2004; 92:45-49.

13. Levey AS, de Jong PE, Coresh J, El Nahas M, Astor BC, Matsushita K, et al. The definition, classification, and prognosis of chronic kidney disease: a KDIGO Controversies Conference report. Kidney Int. 2011 Jul;80(1):17-28.

14. Danziger RS, Tobin JD, Becker LC, Lakatta EE, Fleg JL. The age-associated decline in glomerular filtration in healthy normotensive volunteers. Lack of relationship to cardiovascular performance. J Am Geriatr Soc. 1990 Oct;38(10):1127-32.

15. Docherty MH, O’Sullivan ED, Bonventre JV, Ferenbach DA. Cellular Senescence in the Kidney. J Am Soc Nephrol. 2019 May;30(5):726-736. doi: 10.1681/ASN.2018121251.

16. Fliser D, Zeier M, Nowack R, Ritz E. Renal functional reserve in healthy elderly subjects. J Am Soc Nephrol. 1993 Jan;3(7):1371-7. doi: 10.1681/ASN.V371371. 